\title{
Integrated Structural Health Monitoring in steel arches bridges using continuous dynamic monitoring: two case studies in China
}

\author{
Jing GAO ${ }^{1}$, Tao LIU $^{2}$, Bruno BRISEGHELLA ${ }^{3}$ and Giuseppe Carlo MARANO ${ }^{4}$ \\ DOI: $\underline{\text { https://doi.org/10.5592/CO/BSHM2017.5.5 }}$ \\ ${ }^{1,2}$ Department of Civil Engineering, Xiamen University (China) \\ ${ }^{3,4}$ College of Civil Engineering - Fuzhou University (China) \\ E-mails: ${ }^{1}$ gaojing@xmu.edu.cn; ${ }^{2}$ taoliu@xmu.edu.cn; ${ }^{3}$ bruno@fzu.edu.cn; ${ }^{4}$ marano@fzu.edu.cn.
}

\begin{abstract}
Structural health monitoring (SHM) is going to be a standard tool for bridge management as a decision support for maintenance. Different strategies have been proposed in literature, using different devices and data analysis tools. This paper shows how dynamic monitoring system should be an interesting support for maintenance in steel arch bridges subject to marine environmental condition. The case study deals with two steel arch bridges that are fundamental lifeline connections in the island of Xiamen, China. The monitoring system consists in an integrated data analysis from different sources, such as vibrations from accelerometers, strain from linear strain gauge (located on the rigid suspenders, on the vault and on the cross-section of the arch rib of the bridges), and finally environmental conditions considering temperature and humidity. The paper presents results obtained using data stored in a long period under different climate and load conditions, and how they should be used for a reliable bridge management.
\end{abstract}

Keywords: structural health monitoring, bridge maintenance, data analysis, decision support

\section{Introduction}

In the field of structural engineering, there is a recognized need to monitor the health of civil infra-structures. In fact, in the last years the development of heavy traffic on bridges, often structurally deficient or functionally obsolete, has determined an increase of dynamic effects. The control of safety and comfort of bridges needs dynamic testing, an effective technique that can provide useful information for calibrating numerical models, evaluating simulation strategies, retrofitting and maintenance.

Structural Health Monitoring (SHM) is a non-destructive direct technique that allows a continuous or regular measurement of structural and ambient parameters, which includes input tests and ambient tests $[1,2,3]$. In general, tests with measured inputs are conducted on small bridges, while in other cases output-only tests, based on ambient vibrations (generated by wind or traffic), are the only practical and economic way for exciting the structures without disturbing their normal operation. The main goal of SHM is often (a) the experimental evaluation of modification in structural features, checking the evolution as consequence of a progressive damage; (b) identification of structural parameters to check and update numerical models; (c) finally to evaluate the safety or the serviceability of existing structures, quantifying entity and location of damage [4].

The bridge management presents several critical issues that hamper the effective planning and scheduling of the necessary strategies to the preservation of service (traffic flow). Among these problems, both environmental (wind, earthquake) and anthropogenic vibrations caused by daily human activities (building construction, vehicular and rail traffic) should be taken into consideration.

For this reason, decision support by structural monitoring is a fundamental tool for the correct managing of bridge maintenance. The correct meaning of structural monitoring is to measure a set of physical parameters at specific time intervals and allow you to follow the evolution of structural conditions over time.

One of the main parameters to be analyzed in bridge structural monitoring is the vibratory phenomenon, which can be characterized by having a large or a small amplitude. While the large amplitude vibrations can cause extensive damage due to the severe dynamic loads, the small amplitude does not represent an imminent danger, but can affect the structural strength, especially in the bridges that have already been subjected to important dynamic actions. These issues need to be studied so as to evaluate the effects of vibratory phenomena on the bridges. 
Moreover, as an index of structural performance, vibration response of the bridges is strongly influenced by environmental conditions. So, an integrated monitoring system should use other sensors except accelerometers to deal with environmental parameters, such as temperature and wind velocity.

According to integrated analysis of those data, two types of approaches can be followed to evaluate the effects of vibrations on bridges: one refers to mathematical modeling that can analyze various load scenarios and the other is structural monitoring based on experimental methods. Briefly, the necessary tools for structural monitoring consist of a distributed sensing subsystem of facilities and a data acquisition subsystem able to collect data from sensors.

Regarding mathematical modeling, it presents critical issues related to its effectiveness because it strongly depends on the assumptions on which it is founded. . Thus, the approach based on experimental methods is more attractive because they can be used as a support for the calibration of numerical models, as well as to provide direct information about the negative effects of vibration.

Different from the above approaches, in the present study output-only SHM is adopted for the evaluation of vertical traffic-induced vibrations on two very peculiar arch bridges.

Finally, it is worth noting that the effects of moving loads on bridge structures can be investigated by means of powerful computers and advanced numerical methods [5,6]. This approach is based on numerical simulation of bridge-vehicle interaction and also because its complexity can unlikely be adopted for practical purposes. In this context, Structural Health Monitoring can become a fundamental tool to assess the serviceability conditions of existing bridges $[7,8,9,10,11,12,13]$. Output-only test, based on ambient vibrations (generated by wind or traffic), are in fact the only practical and economic means for exciting the structure without disturbing their normal operation.

This paper describes real applications of an integrated bridge monitoring mixing dynamic and non dynamic sensors to support the management of maintenance in two relative important bridges in sea environmental conditions, which connect the island of Xiamen to the mainland in China. The monitoring system involves integrated data analysis from different sources, such as vibrations from accelerometers, strain from linear strain gauge (located on the rigid suspenders, on the vault and on the cross-section of the arch rib of the bridges), and finally environmental conditions considering temperature and humidity. Preliminary results obtained using data stored in a long period under different climate and load conditions are presented as well as how they should be used for a reliable bridge management.

\section{Description of monitoring systems}

Tianyuan Bridge and Wuyuan Bridge are located in the island of Xiamen, China, crossing the Wuyuan Bay. So, they are located over sea and close to the coast, which constitute conditions suitable for corrosion and thus cause section losses. Also, wind forces are significantly higher in this coastal region. To improve their maintenance and predict possible problems ahead of time, continuous monitoring of these structures can be considered as a promising approach.

\subsection{Tianyuan Bridge}

Tianyuan Bridge is a half-through steel arch bridge with a span of $120 \mathrm{~m}$ and width of $32 \mathrm{~m}$, as shown in Fig. 1 . The arch axis is parabolic. The single box arch rib is located in the middle of the deck girder. The deck is connected with the arch rib by 14 rigid suspenders with a spacing of $6 \mathrm{~m}$. At the intersection, the deck girder is seated at two short spandrel piers over the arch rib. Another two piers support the deck girder at the two ends.

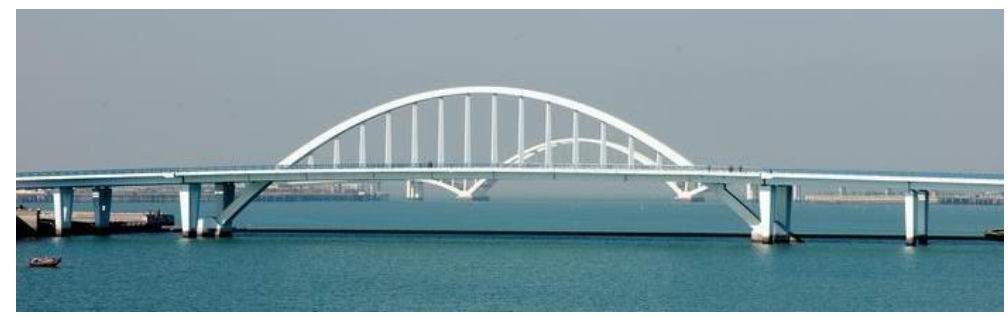

Figure 1 : Tianyuan Bridge (behind is Wuyuan Bridge)

In this real-life bridge monitoring application, the instrumentation plan is designed to monitor the most critical structural components. The current installation consists of more than 100 sensors and summary of the sensors used in SHM system is shown in Table 1. Fig. 2 shows the positions of these sensors. 

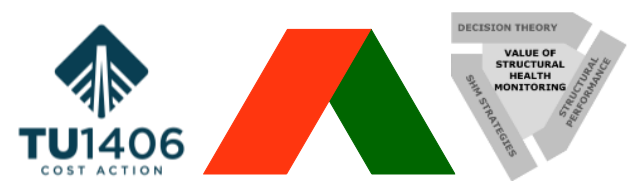

Table 1. Sensors deployed for SHM of Tianyuan Bridge

\begin{tabular}{|c|c|c|c|c|}
\hline No. & \multicolumn{2}{|c|}{ Parameter } & Sensor type & Amount \\
\hline \multirow{2}{*}{1} & \multirow{2}{*}{ Environmental effect } & Temperature & Thermometer & 4 \\
\hline & & Humidity & Hygrometer & 4 \\
\hline \multirow{2}{*}{2} & \multirow{2}{*}{ Loading sources } & Weigh-in-motion system & & 6 \\
\hline & & Traffic condition & Video Camera & 2 \\
\hline 3 & \multirow{5}{*}{ Structural responses } & Tension in hanger & Strain sensors & 20 \\
\hline 4 & & Deflection at arch crown & GPS & 2 \\
\hline 5 & & Vibration in deck girder & Acceleration sensor & 30 \\
\hline 6 & & Strain in arch rib & Dynamic strain sensor & 16 \\
\hline 7 & & Strain in deck girder & Dynamic strain sensor & 42 \\
\hline & & Total & & 126 \\
\hline
\end{tabular}

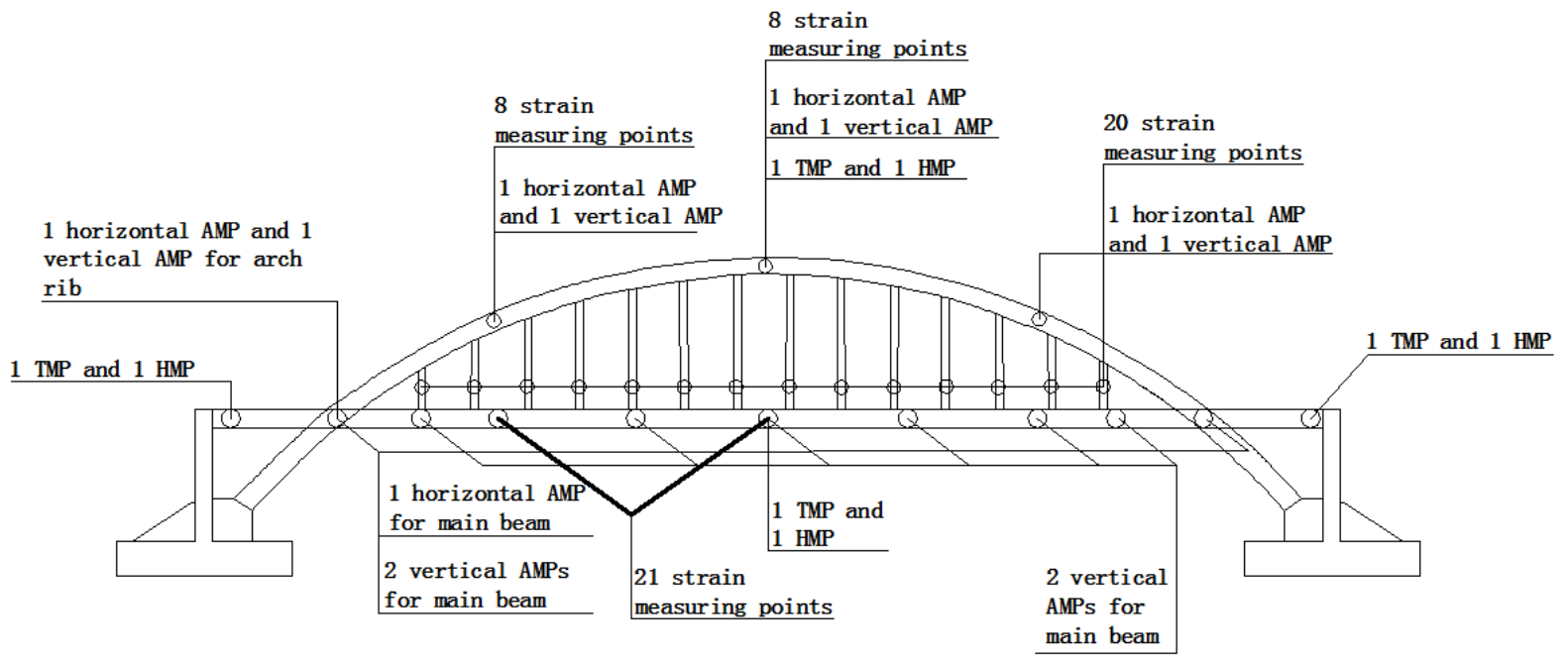

Fig. 2 Arrangement of sensors.

(TMP - temperature measuring point; HMP - humidity measuring point; AMP - acceleration measuring point)

\subsection{Wuyuan Bridge}

Wuyuan Bridge is a half-through steel tied arch with a main span of $208 \mathrm{~m}$ and two side spans of $58 \mathrm{~m}$, as shown in Fig. 3. The deck system is steel-concrete composite girder. The SHM system devised for Wuyuan Bridge consists of four modules, namely, Module 1 - Sensory System (SS), Module 2 - Data Acquisition and Transmission System (DATS), Module 3 - Data Processing and Control System (DPCS), Module 4 - Structural Health Data Management System (SHDMS). The SS and DATS modules are distributed inside the structure, while the DPCS and SHDMS modules are placed in the monitoring and control room. 


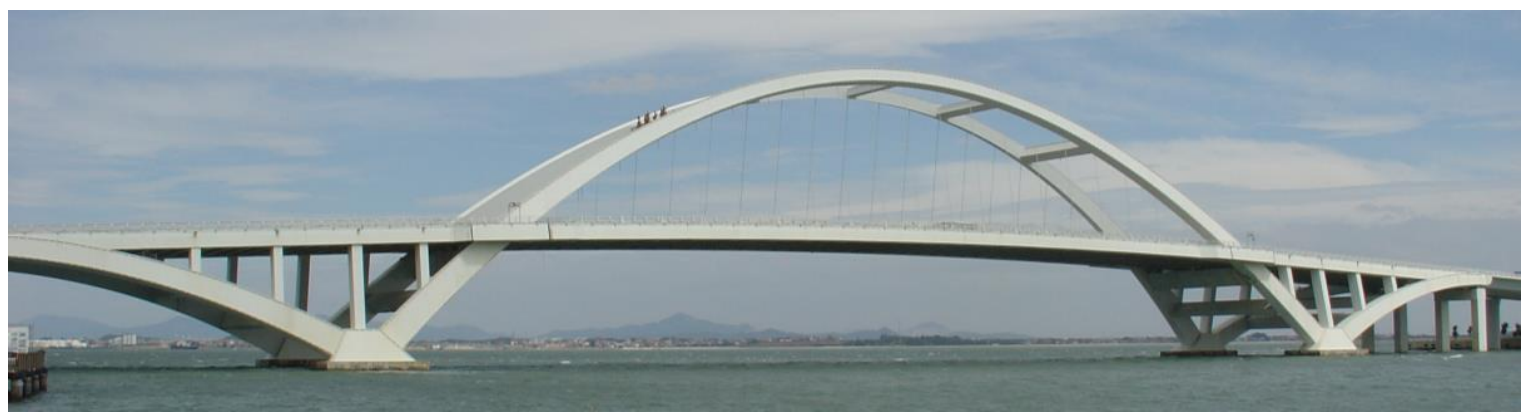

Fig. 3 Wuyuan Bridge

The SS module is composed of about 134 sensors in six main types, as listed in Table 2. These sensors are deployed for monitoring of three categories of parameters: (i) loading sources, (ii) structural responses (strain, acceleration, displacement and geometric configuration), and (iii) environmental effects (temperature and humidity). The arrangement of the sensors are shown in Fig. 4.

Table 2. Sensors deployed for SHM of Wuyuan Bridge

\begin{tabular}{|c|c|c|c|c|}
\hline No. & & Parameter & Sensor type & Amount \\
\hline \multirow{3}{*}{1} & \multirow{3}{*}{ Environmental effects } & Wind speed and direction & Ultrasonic anemometer & 1 \\
\hline & & Temperature & Thermometer & 4 \\
\hline & & Humidity & Hygrometer & 4 \\
\hline 2 & Loading sources & Traffic condition & Camera & 2 \\
\hline 4 & \multirow{5}{*}{ Structural responses } & Displacement at arch crown & GPS & 1 \\
\hline 5 & & Tension in hanger & Acceleration sensor & 20 \\
\hline 6 & & Vibration in arch rib and deck girder & Acceleration sensor & 30 \\
\hline 7 & & Strain in arch rib & Dynamic strain sensor & 22 \\
\hline 8 & & Strain in deck girder & Dynamic strain sensor & 50 \\
\hline \multicolumn{4}{|c|}{ Total } & 134 \\
\hline
\end{tabular}

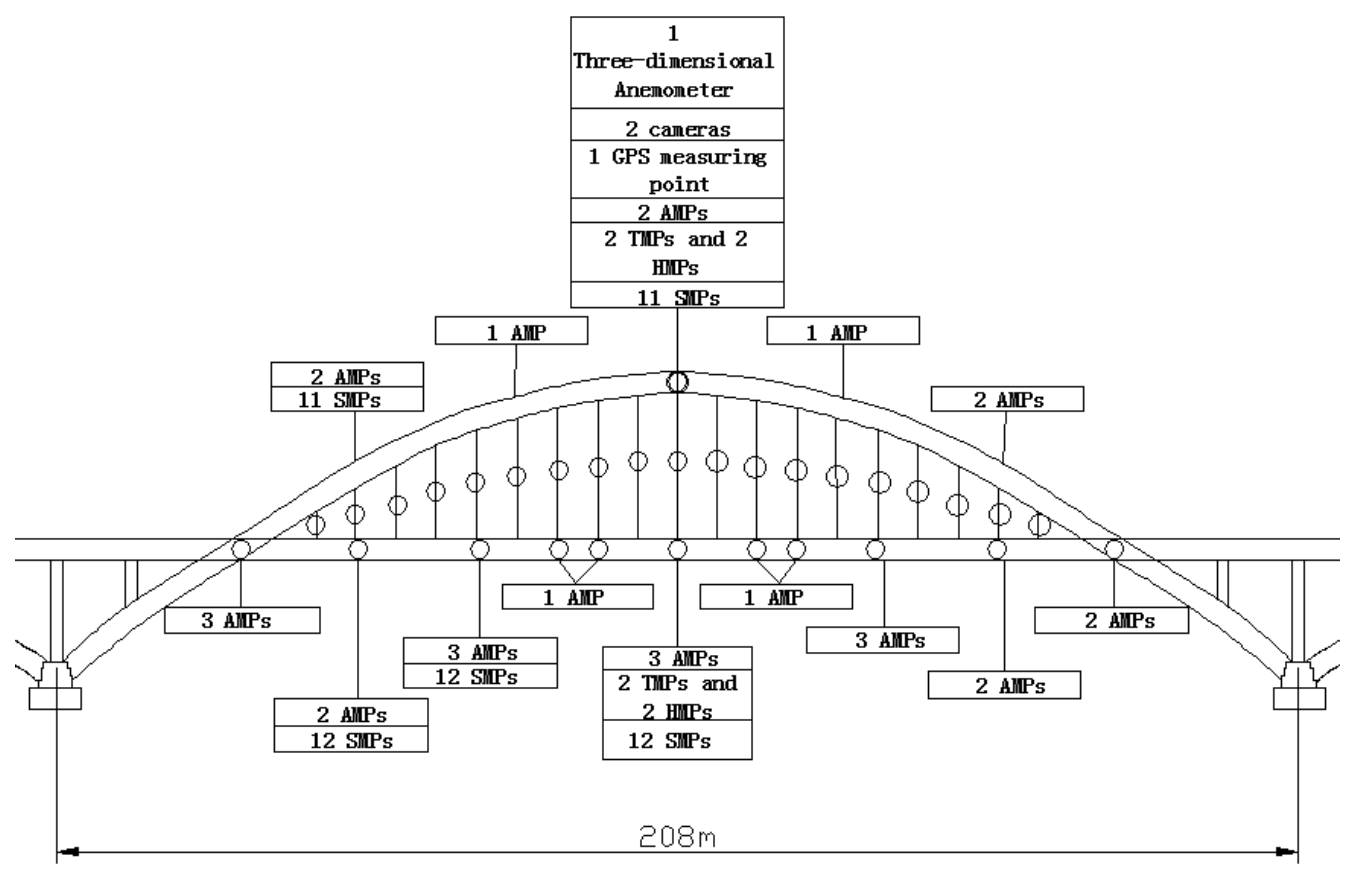

Fig. 4 Sensor arrangement for Wuyuan Bridge

(TMP - temperature measuring point; HMP - humidity measuring point; AMP - acceleration measuring point; SMP - strain measuring point) 

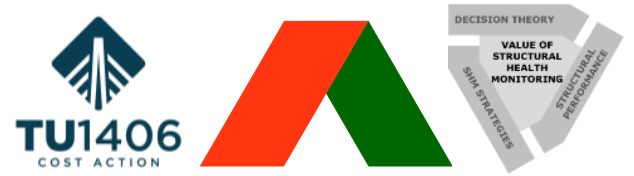

The Value of Structural Health Monitoring for the reliable Bridge Management

Zagreb 2-3 March 2017

\section{Preliminary results from dynamic monitoring}

\subsection{Strain}

The basic principle of strain-based structural health monitoring is that changes in the physical properties of a structure will cause changes in the amplitudes of strain measurements. One significant advantage is that this approach is able to detect and localize damage by analyzing time-domain strain measurements from bridges. Also, the strain-based SHM for damage detection allows the ease of data collection and the flexibility in data analysis when ambient traffic crosses a bridge. The system, having a network of fiber optic sensors, is able to autonomously and continuously collect and manage strain data through wireless communications. The strain data collected from ambient traffic on the bridge are used to extract the quasi-static live-load response.

Based on the finite element analysis of Tianyuan Bridge, the critical sections in the arch rib and deck girder are taken as the concerning section, and totally 78 positions are installed with strain sensors, as shown in Fig. 4. Fig. 5 shows the strain time history at some measuring points. It is demonstrated that within the 10 min time range, the maximum strain reached 125.6u $\varepsilon$ at deck girder, 57.13u $\varepsilon$ at arch crown, 79.13u $\varepsilon$ at the longest suspender and $66.5 \mathrm{u} \varepsilon$ at the shortest suspender.

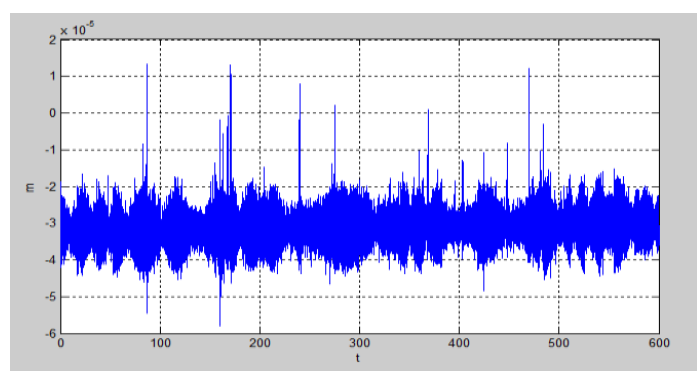

a) At mid-span of deck girder

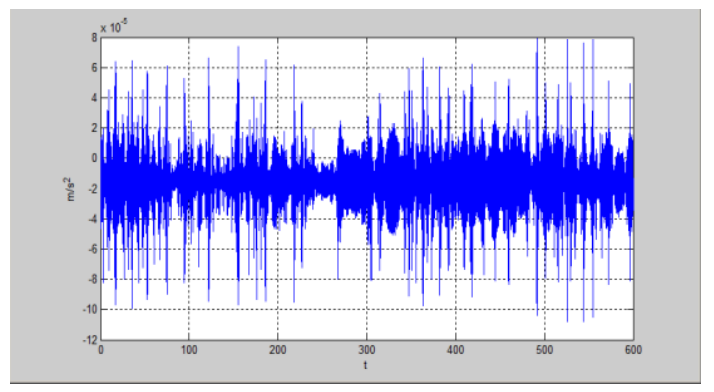

c) At the longest suspender

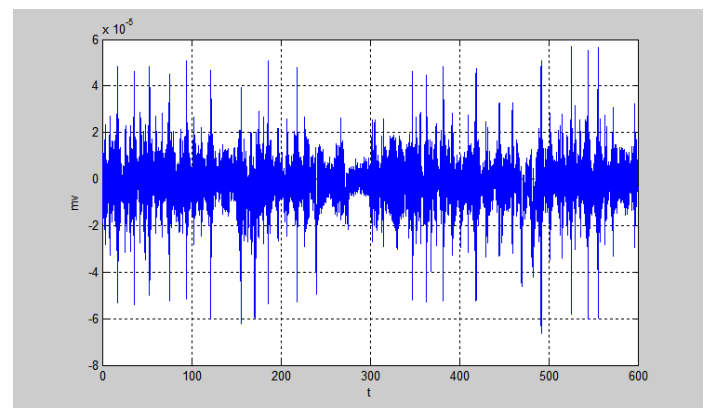

b) At arch crown

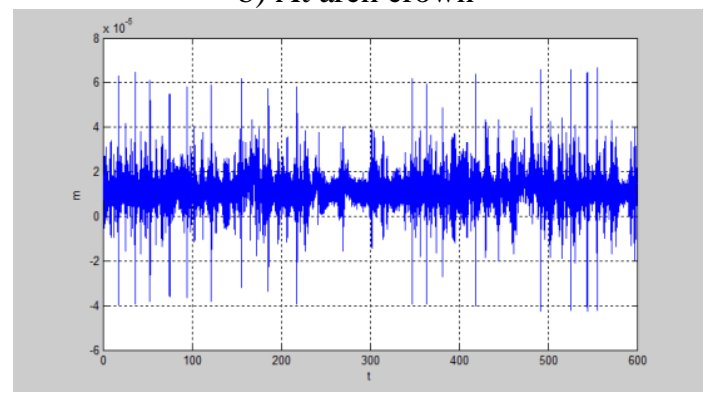

d) At the shortest suspender

Fig. 5 Strain time history at some measuring points

At the mid-span and quarter span of the deck girder, there are totally 21 measuring points for each section. When all the monitoring data at these points are extracted within a time range, the average values can be calculated. Then, the distribution of the strain along the section can be obtained, as shown in Fig. 6. Fig. 7 shows the strain distribution along the mid-span and quarter span section of the arch rib. 


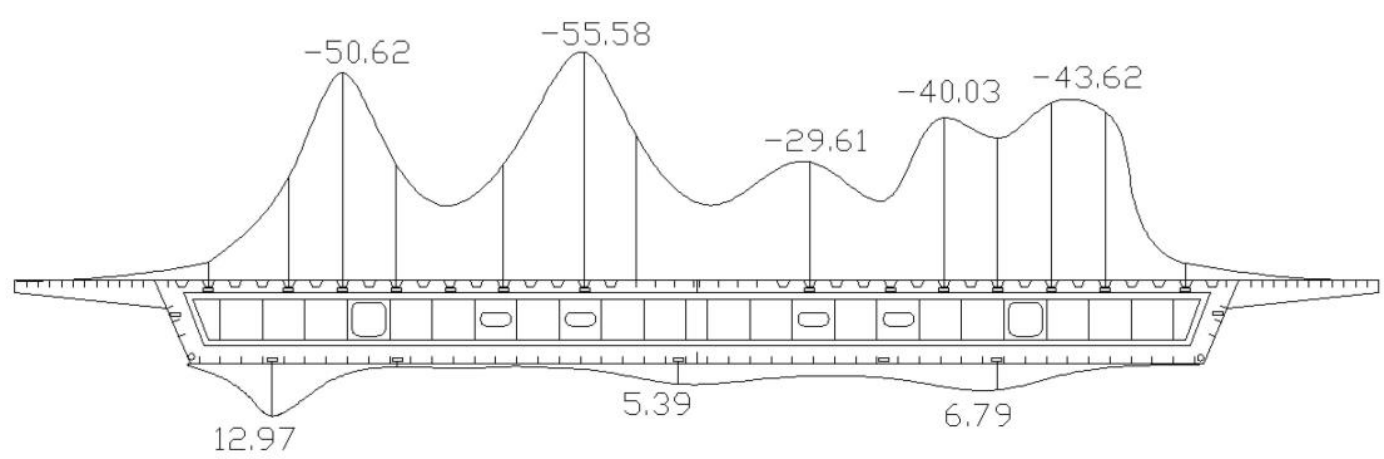

a) At mid-span

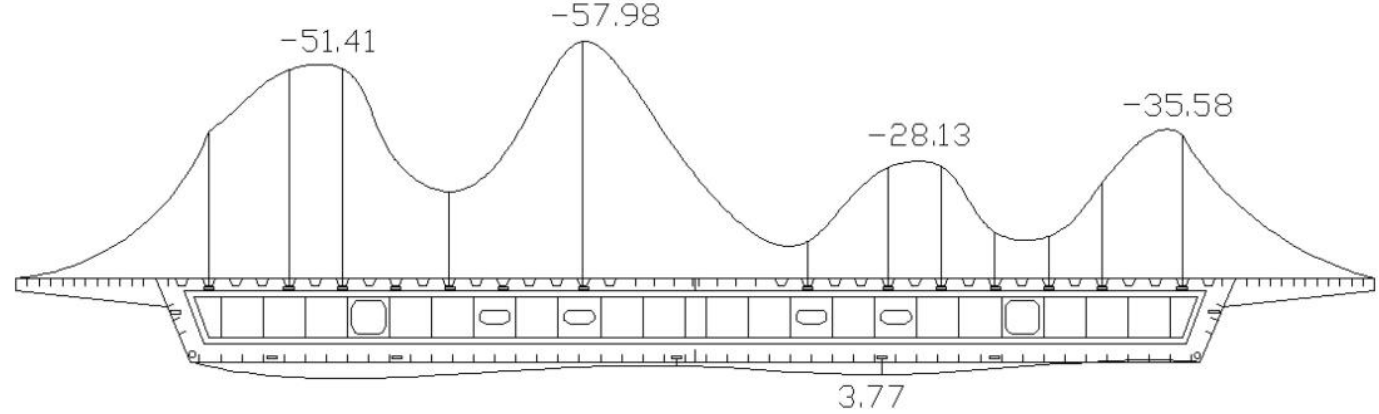

b) At quarter-span

Fig. 6 Strain distribution along the section

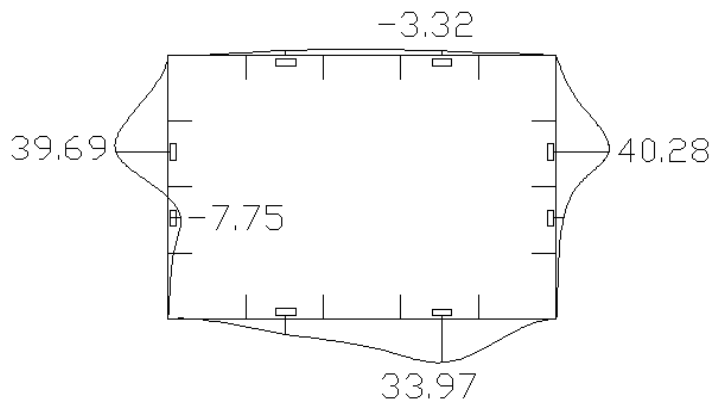

a) At arch crown

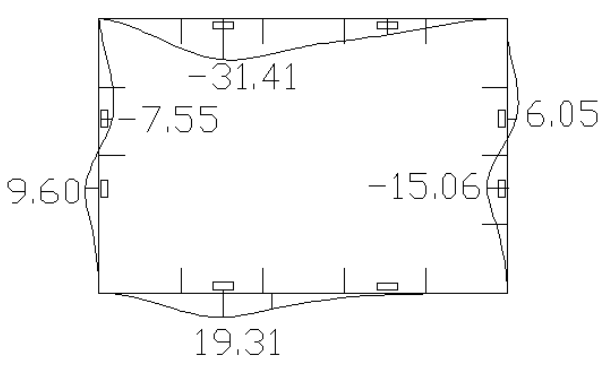

b) At quarter span

Fig. 7 Strain distribution along the section of arch rib

\subsection{Acceleration}

Fig. 8 shows the acceleration time history within one hour at mid-span of deck girder.

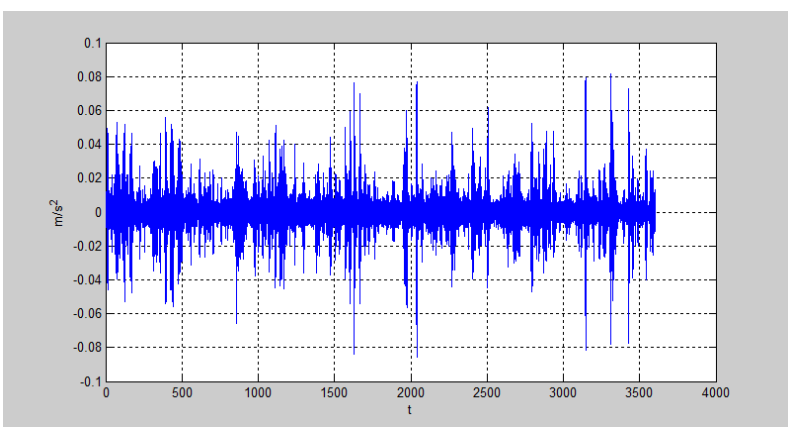

a) Vertical

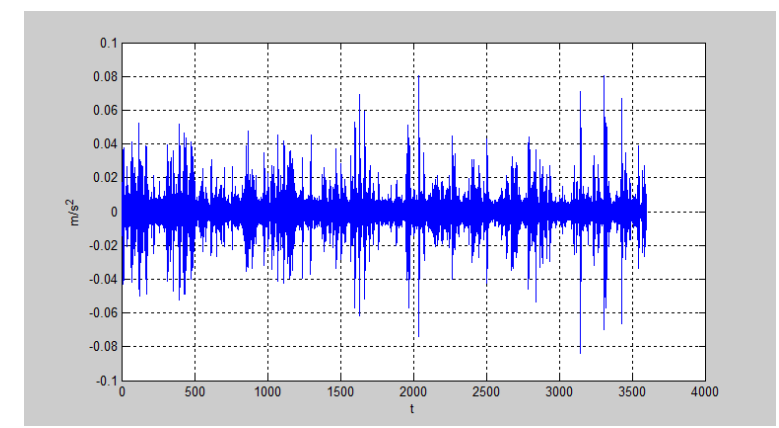

b) Transverse

Fig. 8 Acceleration time history at mid-span of deck girder 

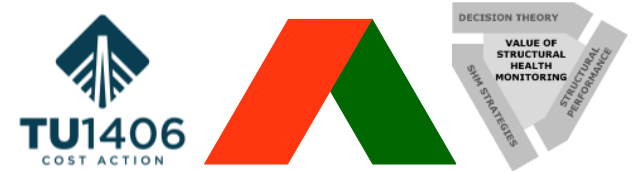

The Value of Structural Health Monitoring for the reliable Bridge Management

Zagreb 2-3 March 2017

\section{Conclusions}

As well known, the aims of adopting a structural health monitoring (SHM) system for bridges are related to damage identification, structural safety evaluation, and maintenance decision making. This paper presents the set up and the implementation of an integrated structural monitoring system in Tianyuan Bridge and Wuyuan Bridge in Xiamen, China. Due to severe marine environmental conditions, an integrated SHM is necessary for bridge management and maintenance. The monitoring system consists in an integrated data analysis from different sources, such as vibrations from accelerometers, strain from linear strain gauge and environmental conditions considering temperature and humidity. Through a long period of structural monitoring under different climate and load conditions, the analyzed SHM systems generate time-specific status information such as bridge vibrations, strain distribution in several cross-sections, displacements, stresses in the hangers and so providing data support for bridge maintenance and decision making, which reduces the maintenance cost and improves the technical level of long-term management.

\section{References}

[1] A. Deraemaeker, E. Reynders, G. De Roeck, J. Kullaa: Vibration-based structural health monitoring using output-only measurements under changing environment. Mechanical Systems and Signal Processing, Vol. 22 (2008), p. 34-56.

[2] A. Fiore, G.C. Marano, P. Monaco. Monitoring of traffic induced vibrations on concrete bridges: a case study. In Proceedings of the 7th International Conference of Bridge Maintenance, Safety and Management, IABMAS 2014, Shanghai, China, 7-11 July 2014, pages 695-702 (2014).

[3] A.Netti, A.Fiore, P.Monaco, G.C. Marano (2015), "Investigation of traffic-induced vibrations on a historic swing bridge in Italy", International Journal of Mechanics, Vol. 9, pp. 53-60, ISSN: 1998-4448.

[4] J.M.W. Brownjohn, F. Magalhaes, E. Caetano, A. Cunha. Ambient vibration re-testing and operational modal analysis of the Humber Bridge. Engineering Structures, 32: 2003-2018, 2010.

[5] H. Moghimi and H. R. Ronagh: Development of a numerical model for bridge-vehicle interaction and human response to traffic-induced vibration, Engineering Structures, Vol. 30 (2008), p. 3808-3819.

[6] G. Quaranta, G.C. Marano, G.C., F. Trentadue, G. Monti. Numerical study on the optimal sensor placement for historic swing bridge dynamic monitoring. Structure and Infrastructure Engineering, 10(1): 57-68, 2014.

[7] Fiore, A., Marano, G.C., Monaco, P., Monitoring of traffic induced vibrations on concrete bridges: A case study, (2014) Bridge Maintenance, Safety, Management and Life Extension - Proceedings of the 7th International Conference of Bridge Maintenance, Safety and Management, IABMAS 2014, pp. 695-702.

[8] Liu T., Zhang Q., Zordan T., Briseghella B., 2016. Finite element model updating of canonica bridge using experimental modal data and genetic algorithm. Structural Engineering International: Journal of the International Association for Bridge and Structural Engineering (IABSE), ISSN: 10168664, Vol. 26, Issue 1 , pp 27-36.

[9] Fa G., He L., Fenu L., Mazzarolo E., Briseghella B., Zordan T., 2016. Comparison of direct and iterative methods for model updating of a curved cable-stayed bridge using experimental modal data. IABSE Conference, Guangzhou 2016: Bridges and Structures Sustainability - Seeking Intelligent Solutions Report

[10] Losanno D., Iuliano M., Briseghella B., Serino G., 2015. Finite element model updating of a highway bridge based on operational modal analysis. Civil-Comp Proceedings, Vol. 108, ISSN: 17593433

[11]Zordan T., Briseghella B., Liu T., 2014. Finite element model updating of a tied-arch bridge using Douglas-Reid method and Rosenbrock optimization algorithm. Journal of Traffic and Transportation Engineering (English Edition), Volume 1, Issue 4, August 2014, Pages 280-292

[12] Briseghella B., Chen A., Li X., Zordan T., Lan C., Mazzarolo E., 2012. Analysis on applicability of health monitoring techniques on a curved cable stayed bridge. Bridge Maintenance, Safety, Management, Resilience and Sustainability - Proceedings of the Sixth International Conference on Bridge Maintenance, Safety and Management

[13] Briseghella B., Siviero E., Lan C., Mazzarolo E., Zordan T., 2010. Safety monitoring of the cable stayed bridge in the Commercial Harbor of Venice, Italy. Bridge Maintenance, Safety, Management and LifeCycle Optimization - Proceedings of the 5th International Conference on Bridge Maintenance, Safety and Management. 